\title{
Lightweight Ribs for the Strengthening of Single Leaf Vaults Undergoing Seismic Actions
}

\author{
FERRARIO Luca ${ }^{1, a}$, MARCHINA Egidio ${ }^{2, b}$, MARINI Alessandra ${ }^{2, c}$, \\ PRETI Marco ${ }^{2, \mathrm{~d}}$ and GIURIANI Ezio ${ }^{2, \mathrm{e}}$ \\ ${ }^{1}$ University of Bergamo, Bergamo, Italy \\ ${ }^{2}$ University of Brescia, Brescia, Italy \\ aluca.ferrario@unibg.it, ${ }^{b}$ egidio.marchina@unibs.it, 'alessandra.marini@unibs.it, \\ 'marco.preti@unibs.it, e ezio.giuriani@unibs.it
}

\begin{abstract}
In this paper the behavior and the collapse mechanism of single leaf vaulted structures undergoing seismic loads are discussed, and an innovative technique based on the use of lightweight ribs is proposed. The efficiency of the solution is verified by means of non linear numerical analyses on a strengthened single leaf vaulted structure. The numeric model is validated through comparison with the results of experimental tests performed on lightweight ribs subjected to cyclic, unsymmetrical load conditions.
\end{abstract}

Keywords: Lightweight ribs, single leaf vault, differential rocking, seismic vulnerability

\section{Introduction}

In the case of a seismic event, the central part of very thin groined, as well as of a single leaf vaults is subjected to pronounced differential deflections due to the unconstrained rocking motion of the abutments and to the horizontal loads distributed along the vault crown (Fig. 1a). It is worth noting that, whether the rocking mechanism can be inhibited or confined, for example by adopting a roof box structure constraining the perimeter masonries along the edge (Giuriani and Marini 2008), the differential deflection of the thin vault induced by the pertaining seismic actions cannot be avoided (Fig. 1b). Depending on the earthquake magnitude and the vault thickness, differential deflection can be as remarkable as to cause the structure collapse (Fig. 1c). During the survey and assessment campaign following the recent Benaco and Abruzzo earthquakes, this mechanism was identified as one of the most frequent collapse mechanism for single leaf vaulted structures.

In masonry vaults equilibrium is guaranteed by the ideal arch developing within the vault thickness (Heyman 1999). The ideal arch is the anti-funicular of the set of applied loads. After cracking, the ideal arch must cross the solid part of each cracked sections, both at the vault key and at the springing. Single leaf vaults are usually very thin, thus the ideal arch has little possibility to shift and modify within the vault thickness to adapt to different unsymmetrical load distributions. As a result, the structure is often quite vulnerable with respect to seismic load distributions, requiring pronounced deviation of the ideal arch.

In order to enhance the resistance of vaulted structures, masonry spandrel walls are traditionally proposed (Giuriani et al. 1999; Gelfi and Capretti 2001). The structure resistance is increased by increasing the thickness of the vaults, thus allowing the ideal resisting arch to adjust within the spandrel wall thickness. However, in the case of single leaf thin vaults attention must be paid to avoid significant dead load increase, which could in turn result in additional seismic actions.

In this paper, lightweight ribs are proposed as an innovative solution to upgrade the seismic performance of existing single leaf vaults (Fig. 2a). Ribs are simply located overlaying the vault extrados profile (Fig. 2 b), and designed to provide the existing vault with a passive confinement. No shear transfer other than friction is allowed along the vault-to-rib interface in order to prevent or limit the vault decompression. This way, in static conditions, the vault dead load is supported by the existing masonry vault, which maintains the original compression state provided that its profile is 
approximately equal to the dead load anti-funicular. In seismic conditions, the lightweight rib constrain the vault deformations, thus providing passive confinement. It is worth noting that, should the strengthening rib be connected to the vault, then the relaxation of material might cause the migration of the loads to the stiffer structure over time, thus reducing the compression stress state in the vault. The compressive stress reduction would result in a major vulnerability of the vault in the case of a seismic event, provided that the vibration might cause the detachment of the brick from the decompressed vault ring.

The rib tubular cross section is made of lime mortar reinforced with glass fiber plaster mesh; the inner lightweight core is made of polystyrene elements (Fig. 2a).

The performance of the proposed technique is verified by comparing the behavior of an unreinforced single leaf vault subjected to horizontal seismic actions with the structural response of a strengthened vault. To this end non linear numerical analyses are performed. The numerical model is validated through comparison with the results of experimental tests on lightweight ribs subjected to cyclic, unsymmetrical load conditions.
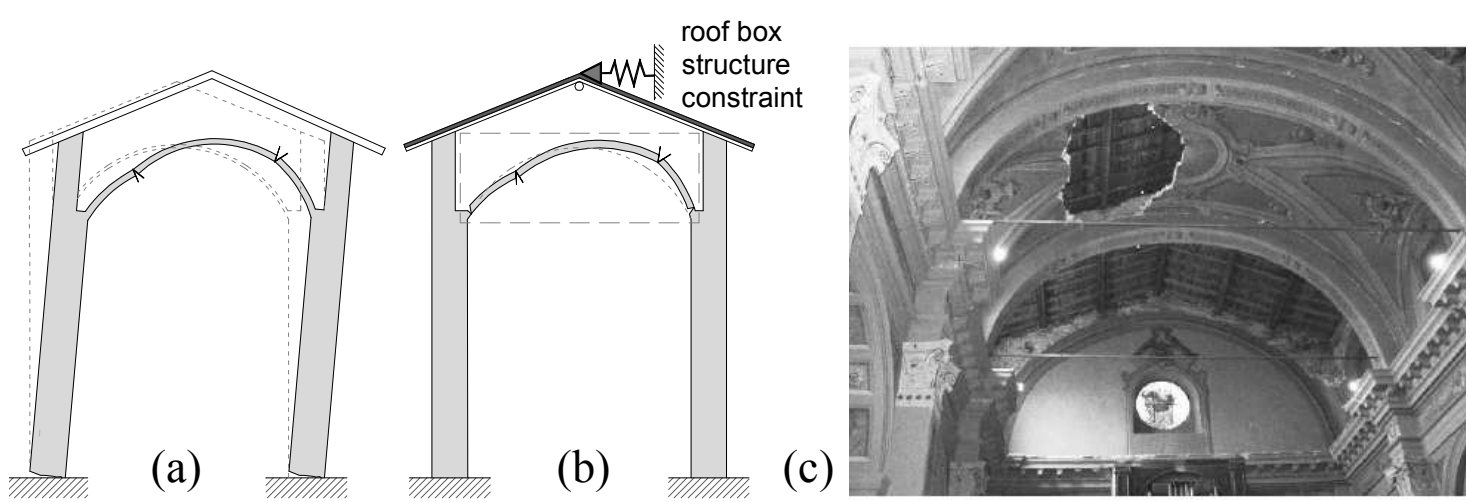

Figure 1: Thin leaf vault subjected to differential deflection following: (a) the unconstrained abutment rocking motion and (b) the pertaining seismic loads. (c) View of S.Pietro Church main nave: total and partial collapse of barrel vaults of the first and second bay induced by the differential deflection of the single leaf groin vaults and by the abutment differential rocking motion

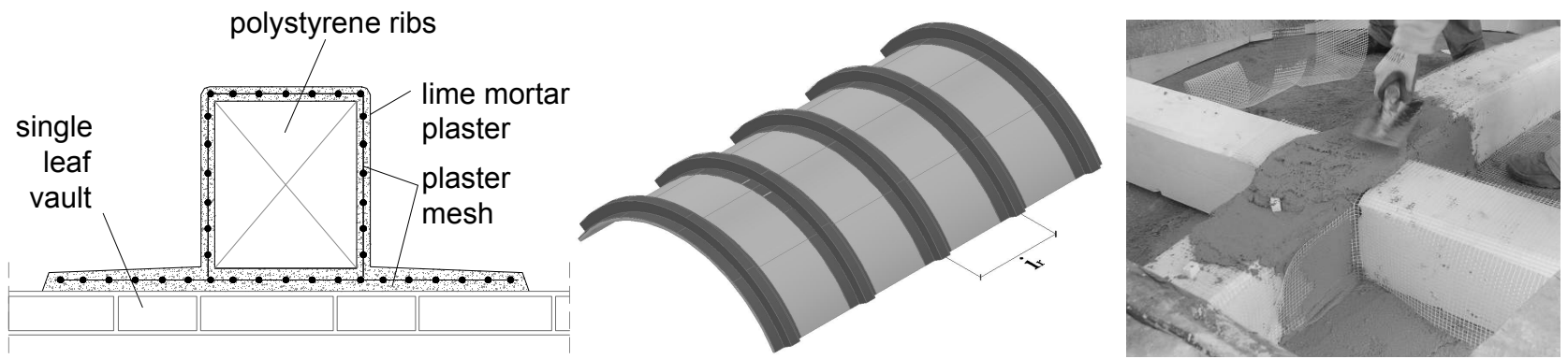

Figure 2: Lightweight rib cross section; distribution of the strengthening ribs along the vault extrados; and view of a construction phase

\section{Seismic Vulnerability Assessment of Existing Single Leaf Vaulted Structure}

In the following, reference is made to a single leaf barrel vaulted structure, in which the abutment rocking motion is inhibited by a roof box structure (Fig. 2b). Accordingly, focus is made to the vault crown only, fixed to the abutment and subjected to the pertaining uniformly distributed seismic actions only (Fig. 3a). The dead load is neglected provided that, given the reduced thickness of the single leaf vault, the vault profile is usually very close to the ideal natural arch, thus the vertical loads are expected to cause axial compression only. Fig. $3 \mathrm{~b}$ shows the bending moment distribution in the elastic field. Plastic hinges in the collapse mechanism are supposed to form where the bending moment is maximum or minimum along the vault crown, namely: at the vault imposts (Sections A, B) and where the shear internal force is nil (Sections $C$ and D identified by $\beta^{*}$ in Fig. $3 b$ ). Once the 
plastic hinges are located, the collapse multiplier $(\lambda)$ can be evaluated with reference to the limit analysis, by applying the principle of virtual work, i.e. by enforcing $L_{e}=0$ (Fig. 3c, d).
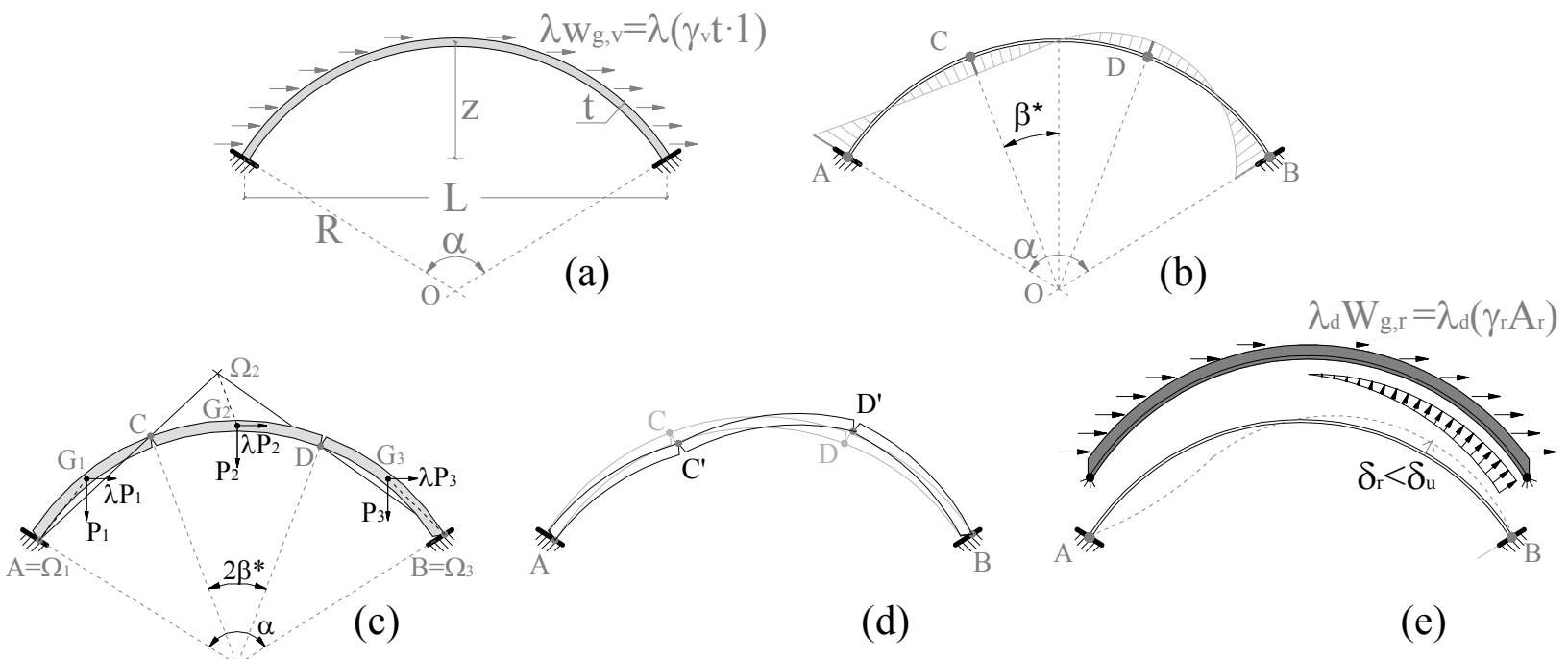

(d)

(e)

Figure 3: (a) single leaf vault subjected to seismic action; (b) sections of maximum and minimum bending moment, corresponding to the location of the plastic hinges in the collapse mechanism; (c,d) Collapse mechanism

\section{Lightweight Rib Design Criteria}

In the likely event that the collapse multiplier $(\lambda)$ be smaller than a design value $\left(\lambda<\lambda_{d}\right)$, the single leaf vault strengthening is necessary. Lightweight ribs are simply supported at the abutments and located overlaying the vault extrados. In order to avoid or limit any possible vault decompression, no shear transfer is allowed along the vault-to-rib interface. In static condition the dead load bears on the vault ring only, inducing compressive internal forces; whereas when seismic actions are considered, the lightweight rib provides a passive confinement to the vault. Accordingly, the rib can be designed to constraint the uplift deflection of the right side of the single leaf vault (DD', in Fig. 3d). Besides a resistance criterion, the lightweight rib deformation must be also controlled, for the maximum deflexion to be compatible with the single leaf vault limit deformation $\left(\delta_{u}\right)$.

\section{Case Study}

As a case study, San Pietro Church, one of the most severely damaged churches, is analyzed. The church is a XIV century single nave building with side chapels. The cross section is shown in Fig. 7a. A series of four transverse arches subdivides the nave into 5 bays. Each bay is covered by $50 \mathrm{~mm}$ single leaf masonry groined vaults. The apse is covered by a single leaf $50 \mathrm{~mm}$ barrel vault. Following the 2004 Benaco earthquake the collapse of the groined vaults of the first and second bay of the main nave were observed (Fig. 1c), whereas less severe crack patterns were surveyed along the other vaults.

In order to reduce the seismic vulnerability of the church, a roof box structure was organized to constraint the perimeter wall rocking motion. As for the single leaf vaults, lightweight ribs were placed along the vault extrados along the main nave and the apse as shown in Fig. 4b. The target design collapse multiplier was set to $\lambda_{d}=0.16 \div 0.25$ as recommended by a regional standard licensed after the Benaco earthquake. Numeric analyses, as well as simplified analytical models were adopted to evaluate the efficiency of the retrofit technique.

As a first simplified estimate, plastic hinges are assumed to develop where the bending moment is maximum. By reference to the bending moment distribution in the elastic solution (Fig. 2a), plastic 
hinges are located at $\beta^{*}=25.25^{\circ}$ (Fig. 3b), and the PLV yields the collapse multiplier of the unreinforced structure: $\lambda_{\mathrm{TH}}=0.077$ (Fig. 3c).

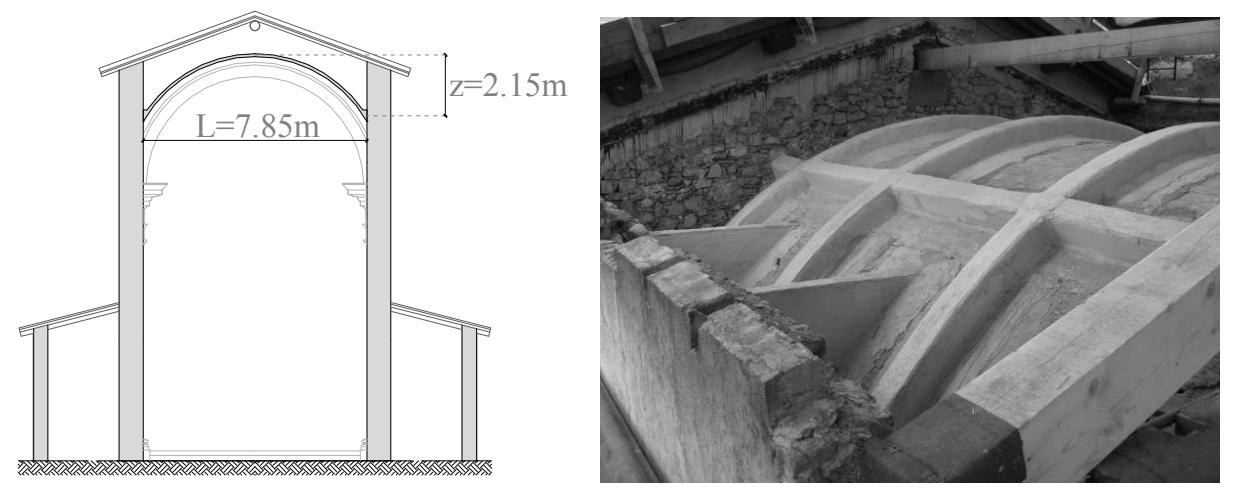

Figure 4: San Pietro Church (Roè Volciano, Brescia): cross section of the apse and distribution of the lightweight ribs along the extrados of the leaf vault

\section{Numerical Analyses}

Non-linear pushover analyses were carried out to assess the vault seismic vulnerability prior and after the retrofit in order to verify the efficiency of the proposed technique.

The heterogeneous and non-linear behavior of the masonry was modeled with reference to a simplified micro-modeling approach (Lourenço 1994): mortar was modeled by means of zero-thickness Coulomb-friction interface elements; bricks were modeled with plain strain elements. Material properties were defined with reference to some preliminary compression tests performed on thin leaf masonry specimens (Giuriani et al. 2007) and to the values proposed by Lofti \& Shing 1994 and Lourenço 1994. Material properties are summarized in Fig. 5a. As for the lightweight ribs, smeared crack elements were adopted to model the thin lime mortar shell, and reinforcement elements were added to model the strengthening contribution of glass fiber mesh. The lightweight rib numerical model was validated through comparison with the experimental test on a full scale rib subjected to unsymmetrical load conditions (see Fig. 7b).
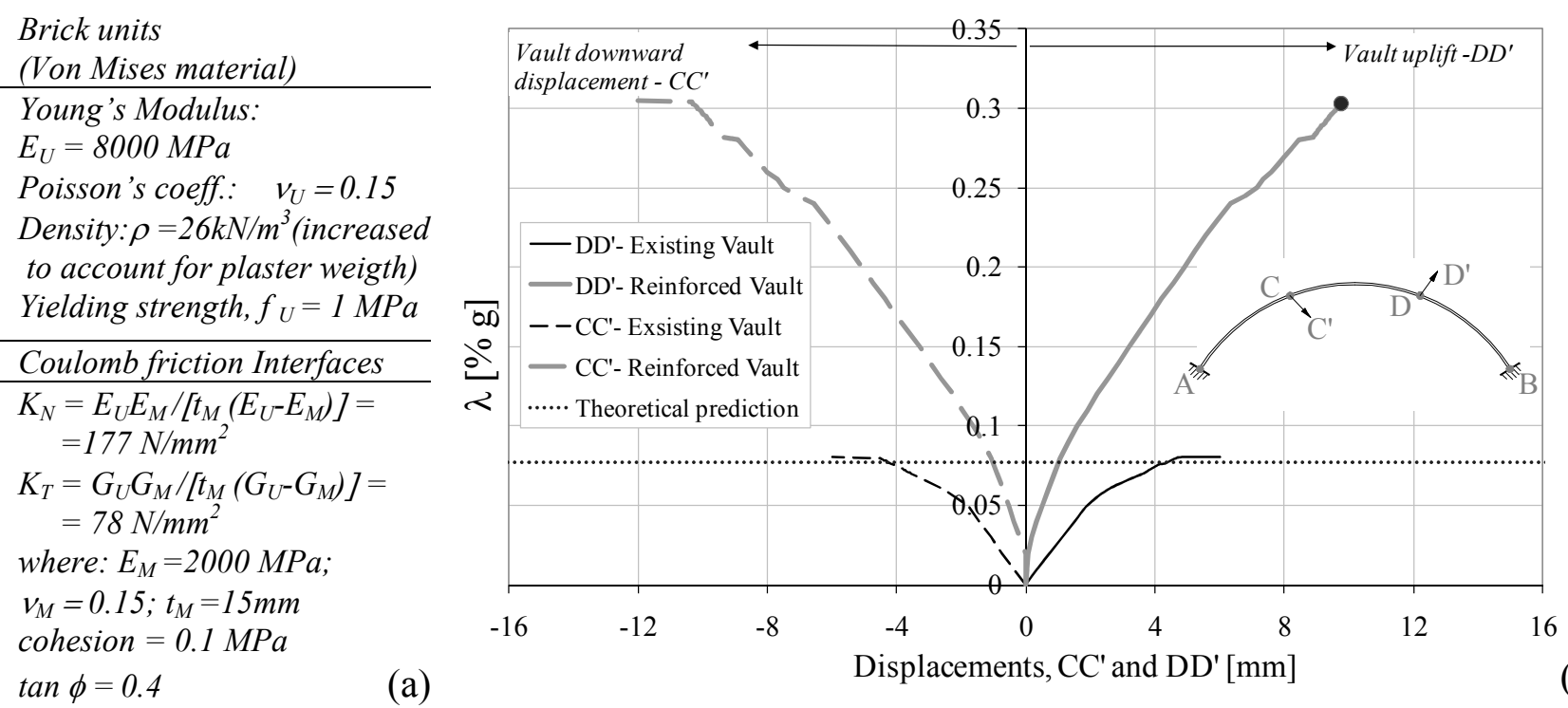

Figure 5: (a) Material properties; (b) Numerical responses of existing vs strengthened leaf vaults

The pushover curves and the deformed shapes of the existing and reinforced structures at the failure mechanism onset are plotted in Fig. 5 and Fig. 6, respectively. The pushover curves were obtained by increasing the seismic load multiplier $(\lambda)$ up to structure collapse and by monitoring the 
uplift and downward displacements of the vault at section $\mathrm{C}$ and $\mathrm{D}$ (CC'-DD'). The increased performance of the reinforced structure both in terms of stiffness and strength can be observed (Fig. 5). The unrealistic plateau of the curves at the mechanism onset follows the assumption of perfectly plastic behavior of the material in compression. Conversely, in the actual structure a softening behavior is expected. Note that no plastic deformation is observed in the reinforced structure uplift-displacement curve, provided the vault is entirely confined by the lightweight rib along the extrados profile. On the other hand the downward displacement increases significantly as the vault detaches from the rib upon triggering the collapse mechanism.

As shown in Fig. 6a, the collapse multiplier of the unreinforced structure, as well as the crack position are well predicted by the analytical procedure illustrated above. The structure vulnerability prior and after seismic retrofit can be assessed by comparing the collapse multiplier obtained for the unreinforced $\left(\lambda_{A}\right.$, Fig. $\left.6 a\right)$ and the reinforced structure $\left(\lambda_{B}\right.$, Fig. $\left.6 b\right)$. Further details of the numeric study are given in Ferrario et al. 2010.
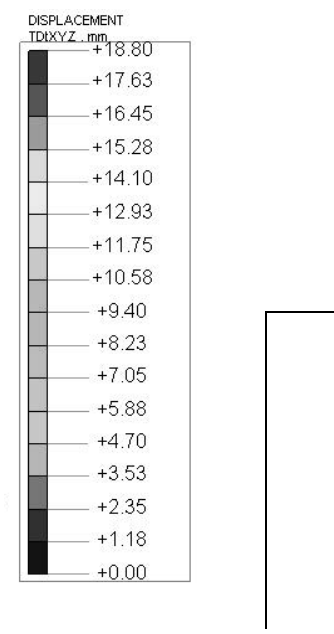
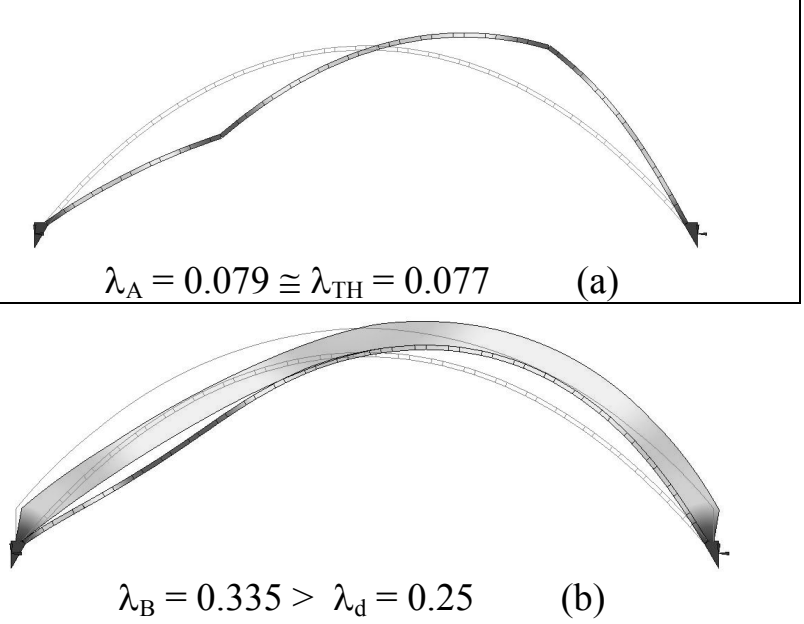

(a)
Figure 6: (a) Existing leaf vault collapse mechanism and comparison with the theoretical prediction of the collapse multiplier; (b) strengthened leaf vault collapse mechanism and comparison with the design target collapse multiplier

\section{Experimental Behavior of Lightweight Rib Subjected to Cyclic Loads}

In order assess the efficiency of the proposed technique and to validate the proposed numeric model, an experimental study on full scale lightweight rib segments undergoing cyclic symmetrical and unsymmetrical loads were carried out (Giuriani et al. 2007). Straight and curved full scale lightweight ribs were tested and good results were obtained both in terms of stiffness and strength.

As an example, Fig. $7 \mathrm{~b}$ shows the envelope curve of the structure response of a lightweight rib segment subjected to symmetrical load conditions, in which the curves recorded during the load cycles are purged. The experimental response is plotted in terms of bending moment versus mid span deflection. A brittle failure occurred for overcoming the shear resistance at the support. However, the ultimate bending moment was approximately 7 times larger than the design value. In the same figure, the numerical response is plotted. The numerical prediction is consistent with the actual structural response (see dashed line in Fig. 7b). Details of the experimental and numerical studies, including different geometries and load conditions, are given in Giuriani et al. 2007 and Ferrario et al 2010, respectively.

\section{Concluding Remarks}

In the case of a seismic event, pronounced differential deflection can be expected along the central part of thin leaf vaults, which can be so remarkable as to cause the structure collapse. In order to 
upgrade the leaf vault performance against this failure mechanism, lightweight ribs are proposed in this paper. Lightweight ribs are placed over the vault extrados profile and no connection other than friction is allowed between the masonry leaf vault and the strengthening element. This special precautions is paid to avoid the vault decompression in static condition. Ribs have a tubular cross section with a lightweight core made of polystyrene elements, covered by a thin layer of lime mortar reinforced with glass fiber plaster mesh. Lightweight ribs are designed to confine the deformation of the existing vaults with respect to the seismic action, by providing the vault with a passive confinement. The efficiency of the proposed technique is verified by means of non linear numerical analyses. Numerical models are validated through comparison with some experimental results.
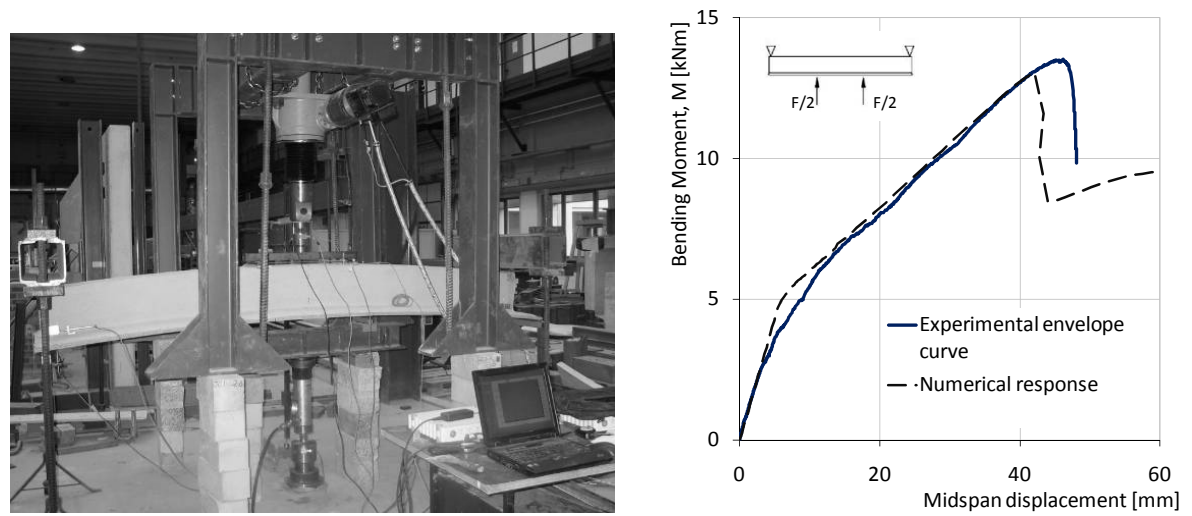

Figure 7: (a) Experimental test on curved lightweight rib; (b) envelope experimental vs numerical response curves

\section{Acknowledgements}

The authors gratefully acknowledge Claudia Porteri for her contribution in carrying out the experimental test. This work was developed within the research project DPC-ReLUIS 2005-2008 Research line n.1.

\section{References}

[1] Ferrario, L, Marini, A, Giuriani, E, and Riva, P (2010). "Seismic vulnerability assessment of single leaf vaults," DICATA, University of Brescia, Tech. Rep.

[2] Gelfi, P, and Capretti, A (2001). "Backfill role on the stability of arches and vaults," in Structural Studies. Repairs and maintenance of historical buildings VII. Wit Press. UK.

[3] Giuriani, E, and Marini, A (2008). "Experiences from the Northern Italy 2004 earthquake: vulnerability assessment and strengthening of historic churches," in VI International Conference on Structural Analysis of Historical Constructions SAHC 2008. 2-4 July, Bath, England. 13-24. Ed. Taylor and Francis, London, UK.

[4] Giuriani, E, Gubana, A, and Arenghi, A (1999). "Backfill and spandrels to limit the vault bending," in Proceedings Stremah 1999. Brebbia and Jaeger. Southampton, Boston, 738-748.

[5] Giuriani, E, Marchina, E, and Porteri C (2007). "Prove di carico su costoloni a rinforzo di volte. (Experimental tests on lightweight ribs)." University of Brescia, Italian, Tech. Rep.

[6] Heyman, J (1999). "The science of structural engineering." London: Imperial College Press. (spanish transl. La ciencia de las estructuras. Madrid: Instituto Juan de Herrera/CEHOPU, 2001).

[7] Lofti, H, R, Shing, P, B (1994). "Interface model applied to fracture masonry structures." Journal of Structural Engineering, 120(1), ASCE.

[8] Lourenço, P, B (1994). "Analysis of masonry structures with interface elements." TNO Building and Construction Research, Rep. 94-NM-R0762. 